\title{
An Evaluation of the Use of a New Virtual Learning Environment for a Postgraduate Hospital Pharmacist Programme
}

\author{
Isobel Bailey \\ Universities of Greenwich and Kent at Medway, Medway School of Pharmacy
}

\section{Introduction}

Virtual learning environments (VLES) are now available in most higher education institutions (HEIs).

Originally most implementation was done at a local level but as the possibilities of technology have become more apparent more is being asked from VLE provision (Weller 2007).

There are a small number of documented examples of VLEs being used to support work-based learning. Gray (2001) described the development of a VLE to support employees working for the British Airports Authority (BAA) who were undertaking a master of business administration (MBA) course delivered and accredited by the University of Surrey. Clarke et al., (2005) discussed the setting-up of a VLE as part of a bespoke managed learning environment (MLE) for the workforce of a healthcare organisation. They concluded that the MLE offered enhanced learning opportunities and assisted healthcare providers in training their dispersed workforces. They also felt that blended learning strategies were the most successful.

The Postgraduate Diploma in General Pharmacy Practice (DipGPP) is a work-based postgraduate programme for newly qualified hospital pharmacists near the start of their careers, which aims to 'equip practitioners with the core skills and competencies they require to provide pharmaceutical care in a practice setting' (Joint Programmes Board).

The students enrolled on this programme work in National Health Service (NHS) hospitals throughout Kent, Surrey and Sussex and are responsible for delivering direct patient care. The development of a portfolio based on experience in the work-place using the General Level Framework (CoDEG 2010), a validated competency framework for pharmacists, is central to the programme. This learning is underpinned by an academic element which consists of face-to face study days or learning sets and the use of workbooks and case studies. Most formative assessment takes place in the workplace so each student has a workbased NHS tutor as well as an academic tutor.

The DipGPP programme is available under the auspices of the Joint Programmes Board (JPB), a consortia 
of HEls working in collaboration with NHS specialist pharmacy services. In recognition of this partnership, students graduate from the programme with both an academic postgraduate diploma and an NHS Statement of Completion of General Pharmacist Training. It is a two and a half year course in total. The first eighteen months leads to a Certificate and then a final year has to be completed for the full Diploma.

Although the programme has been running at the Medway School of Pharmacy since October 2006, it was revised for the cohort of students who joined in September 2011. This new programme is commissioned by Kent, Surrey and Sussex Deanery (KSSD), an NHS organisation which leads on the development of the pharmacy workforce across NHS South East Coast. Delivery of the academic element is now through a formalised partnership between the Medway School of Pharmacy and the University of Brighton, School of Pharmacy.

Three part-time, teacher-practitioners have been appointed as academic tutors, one each in Kent, Sussex and Surrey. Their role is to deliver the learning sets and also run the academic assessments jointly with the programme leader at each university. The delivery of each learning set is repeated three times and is staggered across the counties to provide flexibility for employers and students, so if the local one is missed there is an opportunity to attend elsewhere. There are 39 students registered in the cohort which started in September 2011.

As part of the collaboration with the University of Brighton a new VLE has been developed. This case study describes what was required of the VLE and how it has been developed and used to date.

- Requirements that the new VLE needed to address included:

- Students based externally being able to access course materials.

- Students on the same course being registered at two universities.

- Academic staff based at two universities being able to share teaching materials.

- Work-based tutors working across twelve hospital NHS Trusts being able to access course materials.

\section{Development of the new VLE.}

The VLE was developed over summer 2011 using the University of Kent's External Moodle. After logging in, a user is directed to five modules containing comprehensive information about the DipGPP. These are:

\section{Introduction}

Contains general information about the programme and how it is delivered, including the dates of all the learning sets \& useful links to for example, the JPB website. There are also contact details for the three teacher-practitioners and two programme leaders and maps and travel information for the venues.

This module also contains some working pages for the HEI teams which are hidden from view from the students and work-based tutors. These are very useful for the academic team as we are based at different sites. For example, we have a joint spreadsheet containing all the learning set feedback from the students which we can add to after delivering a learning set. We have also set up a joint repository using Microsoft Word to make sharing and updating course materials between us each year much easier.

\section{Tutor information}


This module mainly contains information for the NHS work-based tutors. There is information about their role and also a Tutor's Handbook as a pdf available for download. There is also a section on tutor support, training and education. It also describes the role of the university based teacher-practitioners.

\section{Diploma in General Pharmacy Practice}

Will contain information once the current students start this part of the programme in March 2013.

\section{Certificate in General Pharmacy Practice}

Contains workbooks and clinical case studies in pdf format for the student to download and work through prior to each learning set. There is also some recommended reading available for download as well as signposting to useful websites.

The teacher-practitioners and programme leaders share the writing of the teaching materials and upload them onto Moodle about a month before each learning set. We are able to share the teaching materials including the answers amongst ourselves but hide them from the students and work-place tutors. There is also information on the academic assessments and guidance on working at masters' level for the students in this module. Academic assessments for this course include a multi-choice question (MCQ) examination paper and writing a 1500 word critical review.

\section{Portfolio Management}

This contains the Portfolio Management Guide which describes all the information that should be included in the student's portfolio. All the proformas needed in the portfolio are available for download. This section also includes a series of DVD clips (produced by the JPB) showing how to carry out the work-based formative assessments required by the programme. This is a very useful tool for both students and workbased tutors which helps to ensure the same learning experience across many different training sites.

\section{How the new VLE has been used to date}

All students were sent instructions on how to register on External Moodle and enrol on each of the five modules before their induction day in September 2011. They were also given the opportunity to ask any questions about it during their induction. Work-based tutors were also sent instructions and they are encouraged to use External Moodle as well because it is the quickest way of accessing up-to-date programme information. The teacher-practitioners and programme leaders attended a short training session in August 2011 to learn how to upload and delete files and to use some of the other features available on the VLE.

94 people have registered as participants since September 2011.

\section{Student feedback about External Moodle}

The 39 students enrolled on to the DipGPP are the most frequent users of External Moodle so in order to try and evaluate how useful they find it they were sent a short questionnaire. Nineteen students replied and their answers are shown in Table 1. 
Table 1 Results of the Questionnaire about the use of External Moodle by DipGPP students

\begin{tabular}{|c|c|c|c|c|c|}
\hline & $\begin{array}{l}\text { Strongly } \\
\text { agree }\end{array}$ & agree & $\begin{array}{l}\text { Neither } \\
\text { agree or } \\
\text { disagree }\end{array}$ & Disagree & $\begin{array}{l}\text { Strongly } \\
\text { disagree }\end{array}$ \\
\hline \multirow[t]{2}{*}{$\begin{array}{l}\text { The instructions for accessing External } \\
\text { Moodle sent out before the course induction } \\
\text { day were sufficient for me to be able to } \\
\text { register successfully. }\end{array}$} & 9 & 8 & 1 & & $\begin{array}{l}\text { 1-was } \\
\text { helped at } \\
\text { the }\end{array}$ \\
\hline & & & & & $\begin{array}{l}\text { Induction } \\
\text { Day }\end{array}$ \\
\hline $\begin{array}{l}\text { Using the instructions I found it } \\
\text { straightforward to enrol onto each of the } \\
\text { modules. }\end{array}$ & 7 & 10 & 1 & 1 & \\
\hline $\begin{array}{l}\text { I find External Moodle to be well laid out and } \\
\text { easy to navigate. }\end{array}$ & 2 & 9 & 5 & 2 & \\
\hline $\begin{array}{l}\text { I find the information contained in the } \\
\text { Introduction section to be useful }\end{array}$ & 3 & 14 & 2 & & \\
\hline $\begin{array}{l}\text { I find the information contained in the Portfolio } \\
\text { Management section to be useful }\end{array}$ & 4 & 12 & 3 & & \\
\hline $\begin{array}{l}\text { I find the information I require about individual } \\
\text { learning sets in the Certificate in General } \\
\text { Pharmacy Practice section easy to find }\end{array}$ & 5 & 13 & 1 & & \\
\hline $\begin{array}{l}\text { I do not have any problems using External } \\
\text { Moodle to download my pre-learning set } \\
\text { study tasks }\end{array}$ & 9 & 6 & 2 & 2 & \\
\hline
\end{tabular}

The students were also asked on a scale of 1 to 10 (where 1 is I do not like at all \& 10 is I like very much) to rate how they like using External Moodle. Sixteen students rated External Moodle at 5 or above with four at 8 and four at 9 . Only one student gave Moodle a 2. Any additional comments made were generally positive.

As this is a work-based programme with some but not all hospitals giving their employees some study-time during their working week we were interested to find out where the students accessed External Moodle. Fifteen replied that they used it at both home and work and one from work only with only three students stating that they had to access it from home.

The students were also asked if there was anything else that they would like to see added to the VLE in the future to help with the DipGPP. Comments included

- Weekly or fortnightly MCQ quizzes perhaps related to the upcoming clinical topic or evidence-based medicine.

- Quizzes, sample MCQs, sample case studies.

.. Use of the calendar function to programme in LS \& assessment dates.

- Videos, podcasts, lectures, extracurricular learning activities such as seminars, challenges such as on site tasks(in workplace) that can be undertaken independently of learning sets.

- Use of the social forum for discussions.

$\ldots$ Answers. 


\section{Reflection}

It is encouraging that so many of the replies we received were very positive. The students attend the learning sets with either a laptop or else the work-books and case studies downloaded and completed (in most cases).

The HEI team jointly agreed at the beginning of the programme that we would not put the answers to the case studies and workbooks on to Moodle. This is a self-directed programme and we want to encourage the students to find out the answers for themselves so that they are able to participate fully during the learning set activities and then use their increasing knowledge and skills in a clinical setting to improve patient care. We also felt that there was a danger that the answers could get passed on to future cohorts as students will be working together in the same hospital pharmacy departments.

All three teacher-practitioners and both programme leaders find External Moodle easy to navigate and use.

As this is a new programme all the teaching materials have had to be written for this cohort which has been very time consuming but in response to the suggestions we received from the students we have recently written our first two quizzes containing practice MCQs using the new updated version of External Moodle (see below). In the future we hope to be able to produce more. Jointly with KSS Deanery we are hoping to produce our first podcast later this year.

Putting all the learning set and assessment dates on to the calendar is a straightforward task and would be useful for all participants. We will do this for the next cohort.

\section{Post case study note}

External Moodle was upgraded on 1st May 2012 to offer a more contemporary look and feel. New features include the facility to navigate more easily between modules and to use Moodle on mobile devices. A new look quiz provides a user-friendly means of undertaking quizzes with options for taking the questions in any order \& flagging questions to come back to. For staff, there are new question types available, with additional mathematical symbols in the HTML.

\section{Acknowledgement}

I would like to thank Dr Shivaun Gammie, Medway School of Pharmacy, for all her hard work setting up the VLE for the DipGPP and to Kaye Bachelard, University of Kent for her help with the additional features available on the new Moodle.

\section{References}

Clark, A.; Lewis, D.; Cole, I.; Ringrose, L. (2005). A strategic approach to developing e-learning capability for healthcare, Health Information and Libraries Journal, 22, 33-41.

Competancy Development and Evaluation Group (CoDEG) (2010). General Level Framework: A framework for pharmacist development in general pharmacy Practice. [Online]. Available at: http://www.codeg.org/ fileadmin/codeg/pdf/glf/GLF_Sept_2010.pdf [Accessed 10/09/12]. 

Compass: The Journal of Learning and Teaching at the University of Greenwich, Issue 6, 2012

Gray, D. (2001). Work-based learning, action learning and the virtual paradigm, Journal of Further and Higher Education, 25(3), 315-324.

Joint Programmes Board. [Online]. Available at: http://www.jpbsoutheast.org/about-the-diploma/ [Accessed 27/04/2012].

Kent, Surrey \& Sussex Pharmacist Foundation Programme (JPB). [Online]. Available at: http://www. ksspharmacy.nhs.uk/foundation-programme-jpb [Accessed 27/04/12].

Weller, M. (2007) Virtual learning environments: using, choosing and developing your VLE, London: Routledge.

\section{Author Biography}

Isobel Bailey has worked as a hospital pharmacist for most of her career. She has specialised in delivering training for all grades of pharmacy staff. In 2011 she was appointed as a teacher-practitioner for the post graduate DipGPP. 